Article

\title{
An Enabling Framework to Support the Sustainable Energy Transition at the National Level
}

\author{
Marina Blohm (1D)
}

Citation: Blohm, M. An Enabling Framework to Support the Sustainable Energy Transition at the National Level. Sustainability 2021, 13, 3834. https://doi.org/10.3390/ su13073834

Academic Editor: Seoyong Kim

Received: 22 February 2021

Accepted: 24 March 2021

Published: 31 March 2021

Publisher's Note: MDPI stays neutral with regard to jurisdictional claims in published maps and institutional affiliations.

Copyright: (C) 2021 by the author. Licensee MDPI, Basel, Switzerland. This article is an open access article distributed under the terms and conditions of the Creative Commons Attribution (CC BY) license (https:// creativecommons.org/licenses/by/ $4.0 /)$.
Department Energy and Environmental Management, Europa-Universität Flensburg, Auf dem Campus 1b, 24943 Flensburg, Germany; marina.blohm@uni-flensburg.de; Tel.: +49-461-8053028

\begin{abstract}
The world is fighting against the impacts of the climate crisis. Although the technical feasibility of $100 \%$ renewable energy systems was already verified by a variety of research studies, there were still more than $200 \mathrm{GW}$ of unsustainable new coal power capacity under construction at a global level in 2018. To achieve the required carbon neutrality, current energy systems need to be transformed toward sustainable energy. The review of the literature has shown that several barriers for carbon-neutral technologies exist, which currently impede the sustainable transition. This paper focuses on the development of an enabling framework to overcome existing barriers to facilitate sustainable and carbon-neutral technologies at the national level. Additionally, it should support decision makers to consider all underlying criteria of this urgently needed energy transition. The criteria of such an enabling framework can be classified in 11 categories, which are (1) environmental and ecological protection; (2) society, culture, and behavior; (3) equity and justice; (4) knowledge; (5) energy markets; (6) energy policy; (7) legal requirements; (8) finance; (9) institutions; (10) infrastructure; and (11) clash of interests. Even though some criteria differ from country to country, a strong governmental support for the transition is always required to be successful.
\end{abstract}

Keywords: energy transition; enabling framework; technology transfer; knowledge transfer; sustainable development; renewable energies

\section{Introduction}

The need for changes in current energy systems to achieve carbon neutrality by midcentury, as determined by the Paris Agreement, is commonly known by policymakers [1]. Increasing the share of sustainable carbon-neutral technologies as soon as possible is needed to be able to decrease the greenhouse gas (GHG) emissions and to limit the global average temperature increase at preferably 1.5 degrees Celsius above preindustrial levels. Even though this knowledge exists and the negative impacts of the climate crisis are more and more present in many countries of the world, the renewably produced share of global electricity in 2017 was just at around 26.5\% [2].

A variety of research verified the technical feasibility of $100 \%$ renewable energy systems (RES) in a number of countries by the year 2050, such as Hansen et al. [3] who published a state of research paper including 180 published articles dealing with the transition toward 100\% RES. According to this work, the majority of studies confirm the technical feasibility of $100 \%$ RES for electricity sectors or a multisector approach. The transformation toward renewable energy or other sustainable carbon-neutral technologies is necessary to limit GHG emissions and to reduce the negative effects of pollution. Countries, such as Portugal for example, already covered $100 \%$ of electricity production from wind and hydro energy throughout the month March in 2018 [4]. However, this is rather an exception than the rule. In 2018, $236 \mathrm{GW}$ of coal power capacity were under construction globally added with $338 \mathrm{GW}$ of planned capacity in preconstruction status [5]. The question why such carbon-dioxide-emitting technologies are still under construction on a large scale needs to be raised. The answer can be found in numerous existing barriers that prevent 
the increasing penetration of renewable energy technologies while promoting fossil fuels, which is demonstrated in this paper.

According to the special report Global Warming of $1.5^{\circ} \mathrm{C}$ of the Intergovernmental Panel on Climate Change (IPCC) [6], total cumulative $\mathrm{CO}_{2}$ emissions amounted to $2230 \mathrm{GtCO}_{2}$ until the end of 2017, and the remaining budget to limit the average global temperature rise to $1.5{ }^{\circ} \mathrm{C}$ until 2050 was at $420 \mathrm{GtCO}_{2}$ (January 2018). Considering the nationally determined contributions (NDCs), $95-130 \%$ of the remaining budget will be spent until 2030. At the same time, the electricity sector just contributed to approximately $44 \%$ to the total $\mathrm{CO}_{2}$ emissions in 2018 [7]. These two aspects indicate the urgent need to foster the decarbonization of all sectors as soon as possible.

A short historical review of how and why the use of fossil fuel accelerated in the past indicates a high inertia of energy system transitions. According to Solomon and Krishna [8] scarcity of wood, technological advances in using coal as the primary energy for manufacturing, electricity generation, transportation, and urbanization were the main reasons for fossil fuels to become the most important primary energy source around the globe. However, this transition from wood to fossil fuels took up to 400 years but resulted in industrial advances to meet the increasing energy demand and enabled rising economic activities. Specific historical events such as the OPEC oil embargo in 1973/1974 forced countries to quickly replace the previously high amount of oil with another cheap energy carrier, such as coal and nuclear energy, to limit the negative effects of the following global recession. The oil embargo required a rapid response of governments to decrease the dependence of oil imports and, optimally, increase the use of domestic or widespread resources.

However, energy from fossil fuels was cumbersome to develop and respectively expansive, which is one of the reasons, why the production of fossil fuel was initially promoted and is still being promoted through political and financial measures today [9]. Nowadays, affordable energy is vital to guarantee the access to energy for all and to enable the competition among global market players. However, an implementation of new technologies, such as renewable energies, needs to be promoted as long as a fair competition with existing technologies is possible [10]. Otherwise, distortive market effects or other inequalities prevent an increased integration of new market players. Nevertheless, neither the pure transfer of technology and knowledge nor the sole design of a nondistortive policy framework indicate that a successful promotion of renewable energies on a large scale can be achieved as other criteria can prevent the transition of entire energy systems. An enabling framework that encompasses a full set of conditions and requirements (hereinafter named criteria) to overcome all existing barriers that prevent the penetration of renewable energy technologies (RETs) [11] is required. The removal of barriers should involve all potentially affected stakeholders such as policy makers, companies, or members of the public through participation and capacity building to gain a broad acceptance of the population [12]. Most of the criteria are not related to technical issues [13] but depend on reducing barriers on dissemination and transfer of technology, mobilizing financial resources, supporting capacity building in developing countries, and other approaches to assist in the implementation of behavioral changes and technological opportunities in all regions of the globe [13]. Barriers can be very individual and "may be specific to a technology, while some may be specific to a country or a region" [11] (p. 3). The entirety of framework criteria can be seen as a module kit, with which each country or region can build upon their specific framework.

This paper focuses on the development of an enabling framework to overcome existing barriers to facilitate sustainable and carbon-neutral technologies at the national level. Additionally, it should support decision makers to consider all underlying criteria of this urgently needed energy transition. The development of such an enabling framework provides structured knowledge on existing barriers as well as key enablers to support the increasing use of clean technologies. However, the presented criteria are not just focused on the construction of clean technologies but on the transformation of the entire social 
system including aspects such as social equity and distribution. Therefore, it is important to understand the linkages between the human social system, the environment, and the energy system, which is described in Section 3. The technical feasibility of such systems is not questioned as the analysis of 180 publications is plausible and comprehensible verified [3]. However, a detailed framework that guides decision makers through the energy transition is important, as the transition currently stagnates in many countries although the remaining carbon budget just gives little time to still limit the negative impacts of the climate crisis. The state of the research concerning existing barriers to renewable energies followed by the gaps in current research is presented in Section 2. Section 3 describes the categories and criteria of the enabling framework in detail. Section 4 focuses on a discussion about further research and recommendations. The paper ends with a conclusion in Section 5.

\section{Materials and Methods}

Current energy systems are dominated by the use of fossil fuel resources and the transition toward sustainable and carbon-neutral technologies seems to progress very slowly in many countries around the world. Therefore, this paper deals with the identification of barriers and enablers to facilitate the energy transition at the national level. The following research questions are answered: (1) Which dimensions and criteria can act as barriers or enablers for sustainable and carbon-neutral technologies to support the reduction of fossil fuel technologies? (2) Which criteria of an enabling framework are most important when analyzing the national level of the energy transition? In other words, which criteria seem to be more important at the regional, business, or project level? (3) Which criteria are important to strive for the decarbonization of the entire systems and thus, are important to push sector coupling? (4) Which criteria can or should be treated differently from country to country?

The enabling framework was developed through an extensive literature review and analysis. The following Section 2.1 summarizes the main findings of this analysis and includes the most important motivations transforming existing energy systems. Section 2.2 describes the gaps of current research concerning an enabling framework. Both sections combined lay the foundation for the developed enabling framework in Section 3.

\subsection{State of Research}

The literature review included both scientific literature and gray literature and was mainly focused on the national level of the energy transition. Enabling framework, enabling environment, renewable energy barriers, and technology transfer were relevant keywords to identify appropriate literature. The limitation of analyzing the national level of the energy transition was chosen to generate an overall approach that is not limited to the transfer of clean technologies or the implementation of policies for specific projects.

The term enabling framework is not consistently defined in existing literature. Sometimes, the term enabling environment is used instead but focuses on the same content. It is often used by addressing only one field of transformation, such as the transfer of technology or the necessary policy framework to support renewable energies, but not by including all criteria that are relevant to successfully transform entire energy systems toward sustainable and carbon-neutral systems.

One of the earliest international programs that pointed out the importance of necessary measures to support and promote environmentally friendly technologies was the Agenda 21, which was published by the United Nations in 1993 [14]. Accordingly, a successful transfer of environmentally friendly technologies to developing countries is crucial when striving for a sustainable development and reducing poverty and inequalities. That is why it is much more important than just for the sole transfer of clean technologies. It is instead related to the whole system of socioeconomic, cultural, human, environmental, and organizational aspects and emphases combined with the transfer of know-how through capacity building in all the aforementioned areas. However, as stated by one of the proposed activities (Section 34.18. d.) of the Agenda 21, the specific relation to an enabling 
framework is given. The Intergovernmental Panel on Climate Change (IPCC) published in their special report Methodological and Technical Issues in Technology Transfer of 2000, the chapter 4 "Enabling Environments for Technology Transfer" [12]. This publication already considers a wide range of policy tools for the successful transfer of technology and highlights the importance of different participation processes and capacity building. Participation connects different social actors and helps to find good solutions for different countries or regions among the variety of available options concerning technologies or policy tools. However, Pueyo et al. [15] criticized such enabling frameworks for the transfer of technology as they are mostly just successful on the project-by-project basis and not by transforming entire energy systems. In the year 2001, J.P. Painuly published "Barriers to Renewable Energy Penetration; A Framework for Analysis" [11]. Although it describes barriers instead of favorable framework conditions, it is fundamental for further development for this publication as important aspects are already covered.

Scientific literature that deals with the description and analysis of barriers to facilitate the use of sustainable and carbon-neutral technologies can be classified according to the scope, which can be at the international, national, regional, or city level and the business, technology, or process level. The decision to concentrate on the national level was mainly due to the number of available publications and the relationship of barriers and enablers tackling the entire system perspective, which is further described in Figure 1. The national level of the energy transition can be separated in two research areas, which are the energy system modeling perspective and the economic analysis of drivers and barriers to facilitate the use of clean technologies. Country-specific energy system modeling results can, for example, be found in [3,16-18]. These studies lay the foundation for the technical feasibility of $100 \%$ RES. The economic analysis of drivers and barriers to facility the energy transition at the national level can be seen as the next step dealing with the implementation of sustainable energy systems. The focus of this national perspective of the energy transition can either be country-specific countries (cf. [19-21]), on technology-specific (cf. [22-24]) or related to specific criteria (cf. $[11,12,15,25,26]$ such as in this paper. The analysis of these publications has shown that topics such as equity, justice, knowledge transfer, environmental impacts besides $\mathrm{CO}_{2}$ emissions, or the strengthening of the domestic economy are in most of the cases not mentioned at all. However, publications such as [11], [24], or [26] already draw the attention to a variety of the barriers that are also presented in this paper.

Besides scientific publications, there have been substantial contributions from NGOs or nonprofit organizations to give recommendations about a sustainable transition toward $100 \%$ RES, however, without a specific focus on an enabling framework (cf. [27]). Unfortunately, no work describes the totality of an enabling framework in one single approach.

The aforementioned examples lead to the conclusion that the best-designed enabling framework cannot work properly if two basic enablers are missing. According to Pueyo [19], initially, the resource itself (e.g., wind speed or solar radiation) needs to be sufficiently available. Second, if the resource demand is given and the relevant technology and knowledge could be transferred, a governmental support and commitment for the transition must be guaranteed. Such a support must foster the improvement of the local manufacturing and institutional sector instead of preferring the pure import of foreign equipment or workers. However, if countries dispose of high amounts of domestic fossil reserves, the government must be willing to decrease the use of these reserves and consequently stop all related fossil fuel subsidies. Otherwise, no new industry would be able to compete with such existing market players. Solomon and Krishna [8] analyzed different governmental reactions after the oil embargo in the 1970s. Accordingly, governmental decisions were responsible for the success or failure of the energy transition reducing the import of OPEC-oil in Brazil, France, and the United States. These historical developments have shown that well-managed transitions combining the three dimensions of supporting niche and novel innovations, building sociotechnical regimes of social groups and networks, andsustaining sociotechnical landscapes of the exogenous environment are the most successful [8]. 
The motivation behind the transition toward high-share renewable energy systems can vary as well. The authors of [28] name five different motivations that support changes in energy systems:

- Cost minimization of the optimal power dispatch

- Least-cost access to electricity and grid expansion

- Electricity decarbonization accompanied by increased energy independence

- Climate related goals

- $\quad$ Or other cost-minimization objectives

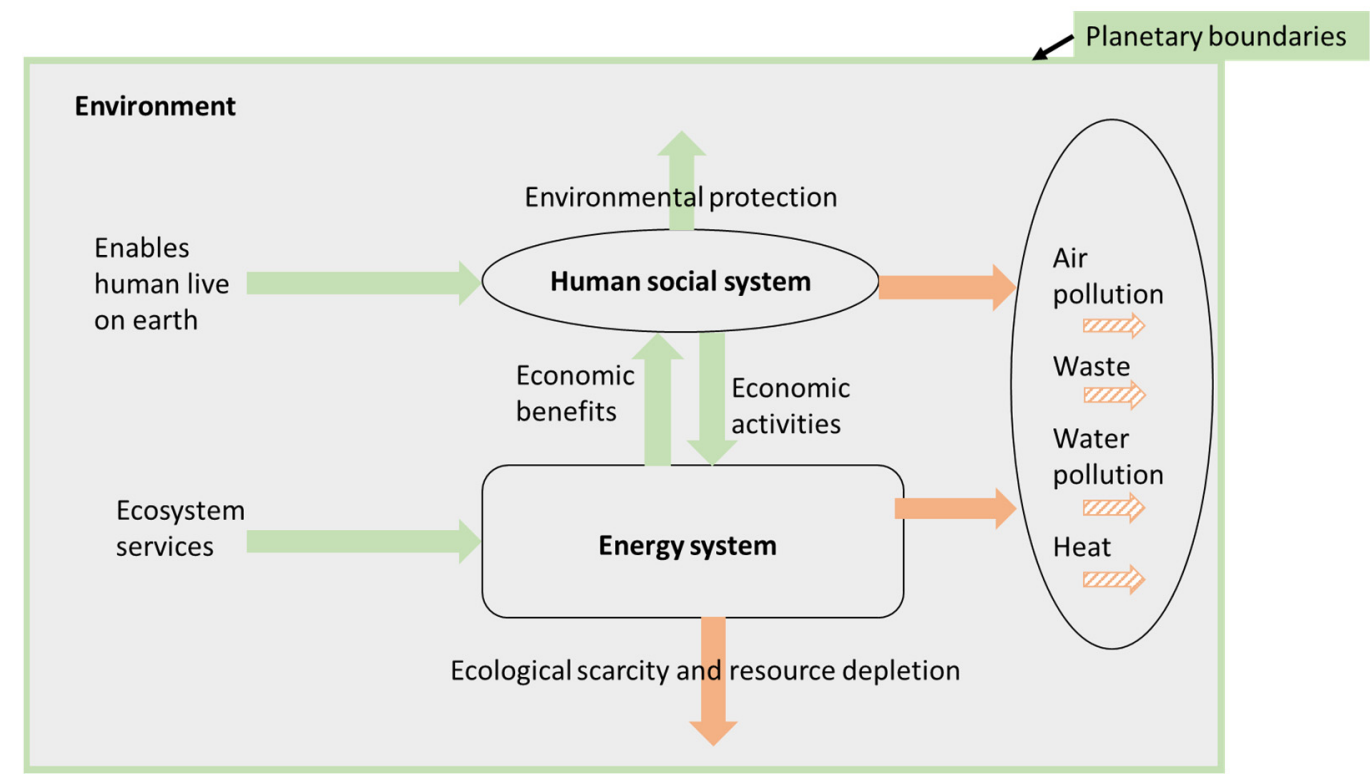

Figure 1. Human-energy-environment trade-off. Illustration based on [29,30] (dark green = positive inputs/outputs; dark orange $=$ negative outputs; striped orange $=$ negative outputs when critical values are crossed).

All motivation results in very different future energy system pathways but most likely achieves the common goal of carbon neutrality. By studying the transition toward 100\% RES to meet the targets of the Paris Agreement, it is assumed that climate change mitigation combined with finding the least-cost solution is the most relevant motivation. In doing so, it is neglected that a number of economies are either financed by the export of fossil fuel resources or are striving for energy independence without having any domestic fossil fuel resources. No matter which motivation stands at the beginning of the transformation, the use of domestic renewable resources can help to achieve the underlying motivations.

\subsection{Gaps in the Current Research}

The research found several aspects that were not included in the analyzed literature but helps to understand the national level of the energy transition and thus forms a comprehensive enabling framework, which tackles the three dimensions of sustainable development: environment, society, and economy. First, the transition of entire energy systems instead of electricity sectors alone is not considered appropriate. The transition of the electricity sector is much easier to handle, as only renewable energy technologies must be supported. The production of renewable electricity has advanced considerably within the last decades, and the priority feed-in of renewable electricity was implemented in a number of countries. The transition of the transportation and heating and cooling sectors is more challenging as electricity must be converted in other sustainable and carbon-neutral fuels. Sector coupling is the term that is used to describe the elimination of all kinds of fossil fuels in the heating, cooling, and transportation sector and to use renewably produces electricity instead [18]. This is also the reason why the enabling framework is not just about increasing the share of renewables but also about decarbonizing entire energy systems. 
Second, as already mentioned in the previous chapter, a lot of progress was achieved concerning the pure transfer of technology toward developing countries. However, this pure technology transfer does not provide as many benefits to the recipient country as it would be possible with the implementation of their own economic and industrial structures. Pueyo [19] analyzes different case studies in which the strengthening of a country's own economic activities leads, in most of the cases, to financial benefits and job creation. However, this publication is very much focused on special projects and not on the transformation of entire energy sectors, which is why this approach needed to be further developed and integrated in the overall approach of an enabling framework.

Third, the importance of identifying knowledge gaps and thus the strengthening of knowledge about the importance of stopping the climate crisis and the criteria of an enabling framework are not prioritized enough in existing literature. Without knowledge or the knowledge transfer, countries would not benefit from a successful transformation. The developed enabling framework includes knowledge as its own independent category and additionally connects other categories with further aspects of knowledge. Finally, most of the analyzed publications talk about existing barriers and not about criteria that need to be fulfilled (cf. $[11,12,25]$. Existing barriers can be specific to a situation of a country, whereas the elaboration of criteria that need to be met allows a better transferability of the entire framework toward different countries or case studies.

\section{Results}

The development of renewable energies has shown that many barriers in different fields exist. The following Figure 1 describes the interdependencies between the environment, the human social system, and the energy system, which is relevant for the further design of the enabling framework.

Environmental economic theories draw the attention to the human-environment relationship; according to which, there is a strong interdependence between the social and economic system and the provision of environmental assets [29]. Other environmental theories analyze the economy-environment trade-off, whereas economic benefits can just be generated while depleting resources and leading to an ecological scarcity [30]. Combining both approaches and linking them to the concept of a sustainable development can help to understand the importance of a comprehensive view on energy generation at the national level. The transformation of energy systems should include the environmental, social, and economic dimension to encompass all positive and negative aspects for the society. Human life on earth has always led to the generation of negative outputs such as air and water pollution, waste, and heat generation. However, we have nowadays reached critical values that urgently require changes in human behavior.

Table 1 names the criteria of an enabling framework for the transition toward $100 \%$ renewable energy systems, which can be summarized in 11 categories under the three dimensions: environment, society, and economy. The 11 categories are (1) environmental and ecological protection; (2) society, culture, and behavior; (3) equity and justice; (4) knowledge; (5) energy markets; (6) energy policy; (7) legal requirements; (8) finance; (9) institutions; (10) infrastructure; and (11) the clash of interests. 
Table 1. Categories and criteria of the enabling framework.

\begin{tabular}{|c|c|}
\hline Category & Criteria \\
\hline Environmental and ecological protection & Planetary boundaries \\
\hline Society, culture, and behavior & $\begin{array}{l}\text { Consumer acceptance } \\
\text { Social acceptance } \\
\text { Public awareness and contributions }\end{array}$ \\
\hline Equity and justice & $\begin{array}{l}\text { Distributional equity } \\
\text { Climate and resource justice }\end{array}$ \\
\hline Knowledge & $\begin{array}{l}\text { School education } \\
\text { Highly skilled workers } \\
\text { Highly skilled policy makers and decision makers } \\
\text { Information and awareness }\end{array}$ \\
\hline Energy markets & $\begin{array}{l}\text { Liberalization of energy market } \\
\text { Elimination of trade barriers } \\
\text { Strengthening domestic economies } \\
\text { Market infrastructure } \\
\text { Ownership structure }\end{array}$ \\
\hline Energy policy & $\begin{array}{l}\text { Regulatory body to promote the use of } \mathrm{CO}_{2} \\
\text { neutral technologies } \\
\text { Good governance } \\
\text { Long-term predictability }\end{array}$ \\
\hline Finance & $\begin{array}{l}\text { Financial co-operations } \\
\text { Economically viable cost structures } \\
\text { Competitive and reliable capital market } \\
\text { Adequate energy pricing } \\
\text { Financial participation }\end{array}$ \\
\hline Legal requirements & $\begin{array}{l}\text { Standards, codes, and certification } \\
\text { Elimination of administrative barriers } \\
\text { Legal aspects }\end{array}$ \\
\hline Infrastructure & $\begin{array}{l}\text { Strengthening existing local infrastructure } \\
\text { Efficient power grid operation }\end{array}$ \\
\hline Institutions & $\begin{array}{l}\text { National systems of innovation } \\
\text { Independent professional institutions } \\
\text { Research and development }\end{array}$ \\
\hline Clash of interests & Lobbyism \\
\hline
\end{tabular}

\subsection{Environmental Dimension of the Enabling Framework}

The transformation of energy systems must combine what is socially just with what are environmentally friendly measures. No data are available that the eradication of poverty, which is the most important social goal at the global level, increases environmental degradation [31]. However, some welfare-increasing developments in industrialized countries have significant influences on the environment. The last decades of research have shown that human activities accelerate the global heating and eventually lead to irreversible changes of environmental degradation and biodiversity loss, if no serious changes in current trends occur. Some of these changes, such as the increasing air and water pollution, the change of land use or the extinction of species, would make life and food production impossible in some areas of the world. That is why the protection of the environment is one important element for the energy transition.

In 2009, Rockström et al. [32] introduced the framework of planetary boundaries, which identified critical values of nine earth-system processes that define a "safe operating space for humanity". Accordingly, all nine processes are interlinked, and the crossing of the critical values can lead to disastrous consequences for human life on earth. Three of the nine boundaries, which are climate change, rate of biodiversity loss, and nitrogen cycle, 
have already crossed the proposed critical values. The necessity of a decarbonized energy sector, which is the focus of this paper, can directly be linked to the boundaries climate change and rate of biodiversity loss. The emission of carbon dioxide from fossil-fuel energy generation accelerates the increase of the global average temperature. In the long-term, this global heating causes significant impacts on the stability of ice sheets, the extinction of species, negative health effects caused by air pollution, or land-use changes, just to name a few [32].

The use of environmentally friendly technologies in the energy sector to achieve a net-zero carbon emission as soon as possible is the only way to stop current trends of GHG emissions. The economy-environment trade-off must clearly favor the careful use of natural resources as well as the emission abatement instead of receiving economic benefits from increasing economic activities. Concepts such as the "valuation of the environment" and the "internalization of external effects" must be integrated in decision-making processes [33]. Otherwise, fossil energy systems appear to be cheaper compared to renewable energy systems, which they are not necessarily [34].

The environmental dimension is highly interlinked with all other dimensions and criteria that are be presented in the following section, as all human actions have a significant influence on the environment. It is therefore not required to specify a number of separate criteria. The reduction of GHG emissions and the limitation of environmental degradation in planning processes are for example integrated in the criteria energy policy (Section 3.3.2) and legal requirements (Section 3.3.4), respectively.

\subsection{Societal Dimension of the Enabling Framework}

The role of the society to drive and foster sustainable development is crucial. The following sections describe the importance of knowledge, equity, justice, and behavior, as these aspects need to be considered because no one and no country should be left alone with the increasing impacts of global heating.

\subsubsection{Society, Culture, and Behavior}

An increased consumer and social acceptance is directly linked to social processes to implement structural changes and to adopting social consequences to support the transition. The normal consumer, who has no environmental-related background, needs information on technologies, products, and the consequences of consumption patter or on environmental-related effects to be able to make informed choices [11,14]. A mixture of product labeling and information campaigns on the advantages of environmentally friendly technologies and products enables the consumer to decide about the consequences of consuming. Energy and environmental-related behavior of people, either individually or collectively, have a great potential for advancing the society but only if governments set the right signals [35]. Furthermore, the social acceptance of the society toward decentralized energy generation must be taken into account and guided carefully. The broad society must be willing to accept changes in current energy systems due to presenting the advantages of renewable energies, for example, and involving local citizens in decision-making processes ideally at a very early stage. Through this approach, citizens have the impression that they can decide on changes and that they are not just confronted with decisions and the underlying consequences. As decentralized power plants could have aesthetic impacts on the landscape, these changes must be communicated neutrally to the local population [11]. The last years have shown that the engagement of the population through specific social movements has increased concerning climate related topics. The movement "Fridays for Future" is just one example of raising voices for a more ambitious climate policy all over the world. The influence of the civil society as well as nongovernmental organizations is important for demanding a stronger governmental focus on the transformation of energy systems. Overall, it can be summarized that the acceptance of the broad population can be very helpful to achieve behavioral changes and consumer acceptance. 


\subsubsection{Equity and Justice}

All aspects of equity and justice need to be cautiously taken into account because the transfer of technology and knowledge can effect different issues of justice and distribution [12]. Poverty and a lack of access to electricity is much more prominent in developing countries. At the same time, those developing countries depend on co-operations and support of industrialized countries due to a lack of knowledge and economic development. That is why a successful collaboration concerning the transfer of technology and knowledge must be beneficial for developing countries to achieve a certain standard of living. Additionally, the most vulnerable countries to global heating are and were not the biggest contributors to the climate crisis, but they must deal with the environmental degradation. The transfer of technology and knowledge can be a chance for developing countries to fight against poverty and environmental degradation at the same time. Besides this co-operation between countries, the consideration of equity and justice on a country-level must be considered [12]. The allocation of newly constructed power plants, the construction of schools or capacity-building institutions, and the implementation of environmental regeneration measures require decisions that directly affect the local population. Such decisions must be transparent and consistent among a country, so that all parts of the population are able to benefit from the transition. On the other hand, the depletion or competition of natural resources must be prevented. Water, for example, that is urgently needed as drinking water or land that is needed for agricultural purposes should not be used for energy production.

\subsubsection{Knowledge}

In most of the publications about an enabling framework, the aspect of knowledge is not as prominent as in this paper, as it is normally just one aspect among others describing the necessity of transferring knowledge toward workers and policy makers. However, the importance of such a knowledge transfer leads to a further analysis. The creation of knowledge begins with a fundamental and appropriate school education. According to the United Nations Department of Economic and Social Affairs [36], there were still more than 260 million children that have no access to school education in 2017 and about 750 million adults remained illiterate in 2016. These numbers show that a fundamental school education is currently not available globally. However, the lack of school education leads to problems in knowledge transfer to workers as basic knowledge is missing. Different case studies in Chile have shown that human capital is crucial for a successful technology transfer to the local economy [19]. Apart from normal workers, policy makers or other decision makers, such as business leaders, need to be well informed about positive and negative impacts of current and future energy systems. Governments can only give appropriate technological signals, if decision makers emphasize the importance of climate change mitigation or other environmental-related aspects. Otherwise, decisions would be made based on aspects of economic growth without considering future generations and global heating. Sometimes, the term "capacity building" is used instead of knowledge transfer. However, this normally does not include school or fundamental education. The adequate knowledge transfer to the whole society requires several aspects. First, prevailing knowledge must be identified to know what knowledge must be trained. Second, the implementation of an institutional framework to enable the scientific, technical, and political knowledge transfer must be built. Third, if training capacities or the required knowledge is not sufficiently available, foreign experts must be involved to build up new training centers. In this way, informed decisions can be made taking into account both economic growth and environmental-related effects. The criterion information and awareness again connect the different categories of the enabling framework as neutral information must be given to the broad population through neutral agencies or institutions, and feedback of the population should be returned to decision makers. 


\subsection{Economic Dimension of the Enabling Framework}

The third aspect of the sustainability triangle is the economy. This dimension includes all aspects of technological, financial, and political criteria that are relevant for a successful transition toward a sustainable economic system.

\subsubsection{Energy Markets}

All aspects tackling the liberalization and organization of the energy sector form the category of energy markets. Numerous market structures impede a free-market competition and thus form one of the greatest barriers for environmentally friendly technologies to enter into markets on a big scale. Some authors, such as John Dryzek, argue that current democracy and governance fall short in achieving emission reduction targets due to "short time-horizons induced by election cycles and the apparent inability of voters to comprehend complex issues" [37] (p. 411). These findings might be correct to achieve a higher social welfare; however, in times where not-in-my-backyard discussions are still prominent, political guidance is required to limit negative impacts of the climate crisis as much as possible.

On a project-by-project basis, these structures may not be as essential as looking at the national energy market because most individual flagship projects are based on special agreements, which suspend unfavorable market structures for these special projects.

A liberalized energy market is the opposite of a highly controlled energy market and is based on different pillars to achieve a free competition among independent market participants. Former energy sectors that were primarily based on big, central conventional power plants were characterized by state-owned utilities, which held the monopoly for the generation, transmission, and distribution of electricity and thus were able to dictate the price for electricity. The deregulation of monopoly structures allows independent power producers (IPPs) to invest in sustainable energy projects and either sell their electricity or use the electricity itself (self-generation) and consequently increase the efficiency of the entire market through market competition [11]. In this way, energy prices are no longer controlled, and big state-owned utilities must compete with the private sector. Such a commercialization of the energy sector also means the unbundling of generation, transmission, and distribution of electricity to allow a real competition price setting [25]. However, not just the deregulated energy market itself is important to increase the share of renewable energies but also the access to and availability of the technology plays an important role. New technologies are usually owned by private (sometimes foreign) companies. The market entry of such companies must not be restricted by trade barriers to allow the import or export of these technologies [19].

Strengthening domestic economies is one key aspect to avoid the pure transfer of technology but to enable an economic benefit for all. Governments must create incentives for foreign companies to build up new local markets for their own production of equipment and electricity, while at the same time training domestic workers to create new jobs [19]. The empowerment of the local economy helps foreign companies to switch to an economically suitable and environmentally friendly industry, while at the same time creating new jobs for locals. One example is the construction of a rotor blade factory in Tangier, Morocco, of the wind turbine manufacturer Siemens Gamesa Renewable Energy to meet the regional demand of wind energy technology. Even if this factory just constructs parts of a whole wind turbine, it generates 600 direct and 500 indirect jobs and is coupled with a training center to guarantee the necessary knowledge transfer toward the domestic society [38].

A well-managed energy sector and the elimination of logistical problems are just two aspects of favorable market infrastructures. The management of entire energy sectors require clear structures and persons or ministries in charge that must work closely together and follow the same goals. If such an efficient and transparent management cannot be guaranteed, ministries would then follow their individual businesses and perhaps counteract necessary developments. The creation of favorable logistical aspects includes 
the construction of supply channels and supply chains as well as convenient business locations and availabilities [11].

The ownership structure of centralized, big fossil power plants can substantially differ from the ownership of decentralized renewable-energy power plants. In Germany in 2004, 38.5 GW of installed coal-fired power plants were owned by five big operating companies [39]. In contrast, only $5 \mathrm{GW}$ of renewable energies were owned by utilities and slightly more than $10 \mathrm{GW}$ by private individuals or farmers [40]. In 2020, these numbers grew to $23 \mathrm{GW}$ and $53 \mathrm{GW}$, respectively. Such a high number of private investments was possible because the renewable energy law in Germany limited the economic risk of investors due to predictable and fixed feed-in tariffs [41]. In this way, the energy transition with its underlying risks is spread over various investors, and the influence of big utilities is restricted. The advantage of private investments or small companies is a fast adjustment of business activities in relation to new innovations and the ability to achieve fundamental changes in energy systems. The administration and possibilities for fast actions is much more restricted and limited for big, mostly listed companies [42]. Advances in nice and novel technologies, which are urgently required to successfully carry out the transition of entire energy systems-apart from the electricity and transportation sector-might be easier to achieve with high numbers of flexible private investors or small companies.

\subsubsection{Energy Policy}

It is important to note that the implementation of a regulatory body to promote the use of $\mathrm{CO}_{2}$ neutral technologies is one of the most crucial aspects to successfully perform the transition toward a $100 \%$ RES. At the same time, the individual design of the regulatory body can differ widely among different countries according to their underlying motivation (see Section 2). Nonetheless, no matter how the specific regulations look like, there are many criteria that are relevant for all energy systems. It is very important that renewable energies or other carbon-neutral and sustainable technologies gain priority access and feed-in to both the electricity and gas grid. In this way, carbon-neutral technologies are prioritized to conventional technologies, and investors get the guarantee that their produced electricity will be used and paid [35]. Besides this compulsory renewable feed-in, there are many different favorable regulations to promote the use of renewables. If governments would like to manage the energy supply via price-driven regulations such as fixed-payment feed-in tariffs (FITs) or via quantity-driven regulations such as quotas, they need to be decide on it individually. A detailed overview and definitions of potential policies can be found in $[25,35]$.

To set the right political framework is probably the most discussed and developed aspect of an enabling environment. The development of the most suitable regulations to promote the use of renewable energy technologies has already lasted since the 1990s, and today, about 126 countries implemented power policies, 68 countries implemented transportation policies, and 21 countries implemented heating and cooling policies [2]. These numbers show that there needs to be much more effort to foster all aspects of sector coupling to incentivize the switch toward green fuels or green gas. This switch is much more complicated because in the transportation and heating sectors, green fuels and green gas are non-natural end-products. The production of such sustainable resources requires either the transformation of entire markets to use electricity as the main source, such as the switch from diesel cars to electrified cars, or the use of electricity to be converted into green gas. In the case of a further use of electricity, the exemption from taxes and levies for electricity end-users must be guaranteed [43]. Furthermore, sector coupling will require much higher electricity demands in the future. One possibility to use already existing additional amounts of electricity is the use of currently curtailed electricity from fluctuating sources. The feed-in management of some countries allows for the curtailment of excess electricity that cannot be injected in the electricity grid due to limited capacities. In 2018, more than 5 TWh of electricity, mostly generated by wind turbines, were curtailed in Germany [44]. Such high amounts of electricity should be used as they do not require 
the expansion of the electricity grid but enable the production of hydrogen as an example instead of paying compensation fees.

Even though the implementation of renewable-energy support policies increased over the last years, the removal of pervasive subsidies for conventional energy remains static. In 2015, all G20 member states paid in total about 4500 billion USD for fossil fuel related subsidies [9]. Such high amounts of investments in conventional energies prevent the transition toward carbon-neutral energy sources but lead to a market distortion. However, as the most important aspect of the transition is the reduction of GHG emissions, the decarbonization of all energy sectors must be the priority [45]. Binding $\mathrm{CO}_{2}$ reduction targets accompanied by either a carbon tax or emission trading scheme can ensure the abatement of $\mathrm{CO}_{2}$ emissions throughout all energy sectors. The implementation of the European Union Emission Trading Scheme (EU ETS) shows that such systems must be well designed to persuade industries to invest in mitigation and abatement instead of just buying more and more allowances whereby no emission reduction can be achieved. If such policy implications to reduce the amount of emissions are not enough, governments should decide to focus on the total phasing out of conventional energy sources like the phase out of coal. Therefore, it is necessary to analyze if countries are just focusing on the mining of coal for exportation, such as Colombia; are using solely imported coal to produce electricity, such as Morocco; or depending both on coal mining and energy production, such as Poland. Measures to compensate negative effects of a coal phase out range between the establishment of know-how and training capacities to enable new employments, the transformation of former coal mines toward areas to produce sustainable electricity, or to convert them into touristic attractions and the connection of remote areas to urban centers to enable the search for new employment possibilities [46,47]. All cases require a detailed country-related analysis of regional and national influences of socioeconomic indicators to identify the most important drivers and barriers to look at the transformation "as a window of opportunity [... ] to transform the regions according to a more sustainable vision" [46] (p. 11).

A well-designed political framework is very crucial to switch on the one hand from a conventional electricity production toward a carbon-neutral electricity production and on the other hand, to enable the coupling of all energy sectors away from carbon intensive energy sources. There is a strong link between this category and the financial, technical, and institutional framework, as a priority feed-in of carbon-neutral energy must be tackled from grid operators and accompanied by financial decisions. Additionally, the progress of the last decades has shown that, from a political side, the transition can be already well managed but a lack in knowledge transfer or lobbyism for conventional energy harm the implementation on a large scale. The influence of lobbyism with be further discussed in Section 3.3.7.

Another very basic but extremely important criterion is a safe environment and good governance. Kaufmann et al. [48] define six dimensions of governance: voice and accountability, political stability and absence of violence/terrorism, government effectiveness, regulatory quality, rule of law, and control of corruption. All these aspects require transparency as well as a strong opposition to enable a strong and powerful polity. This powerful and well-developed polity guarantees the required collaboration between stakeholders and politicians in all sectors using power and water so that a sustainable development toward a decarbonized economy is possible to implement. The absence of corruption is crucial, as corruption probably does not lead to achieve the necessary goals on a just and economically feasible manner.

The importance of a long-term predictability is linked to both aforementioned criteria of good governance and a regulatory body to promote the use of decarbonized and sustainable energy. Long-term predictability includes the development of long-term goals in a transparent, and ideally participatory, manner to enable a strategic planning for all involved market participants. Such a long-term planning possibility reduces the financial risks for investors [35] because it reflects a clear signal of governments toward the 
expansion of technologies or the achievement of goals (e.g., to produce $100 \%$ renewable electricity in 2050) [19].

\subsubsection{Finance}

This category deals with criteria that affect the international, national, and local level. As many developing countries have limited possibilities to finance the reduction of their GHG emissions, international funding possibilities are a very important tool. Besides the Global Climate Fund (GCF) which "is the largest global fund dedicated to help fight climate change" [49], many other international funding opportunities exist. The NAMA Facility, Clean Development Mechanism (CDM), or Global Environment Facility (GEF) are just some of the existing funds that exist besides private investments at an international level. The problem is that a lack in knowledge transfer impedes developing countries to invest in climate-friendly technologies as they cannot finance such a transformation with the help of own financial resources. According to Painuly [11], there are several criteria that are important for the investment in sustainable energy projects at the national level. Economically viable cost structures mean that the cost of capital, labor, resources, or material needs to be competitive and at an adequate level so that it is worth it to transfer the technology or knowledge to the relevant country. The importance of a competitive and reliable capital market heads in the same direction. On the one hand, the capital market must be well developed and reliable so that a long-term planning without uncertainties and risks is possible. Such a predictability also includes stable exchange rates or adequate and stable taxes on profits. Perhaps, capital subsidies can also be a possible incentive for investors; however, they need to run only for a limited time to guarantee improvements in efficiencies. At the other hand, the access to cheap capital, like credits at low discount rates, is important for both investors and private consumers as debt capital plays an important role in costly large-scale energy projects. Finally, the absence of capital market entry restrictions enables investors to invest in the construction of, for example, new production capacities in foreign countries as a way that the foreign country can benefit most from the transfer of technology [11]. The third criterion under the category finance is the adequate energy pricing. This criterion consists of two different aspects. First, the positive as well as negative environmental externalities must be considered in all fields of energy pricing. Negative health effects of pollution caused by conventional energy production, the environmental damage of resource mining, or the damage of nuclear accidents are just some important negative externalities that are mostly not reflected in the price of electricity. Renewable energy technologies have significantly less environment-damaging negative external effects but must compete with conventional energies, which do not consider the underlying external costs (cf. [34]). All financial support mechanisms that are required to support renewable energy technologies, technological advances, or decarbonization of the energy systems were treaded in the category energy policy.

At the local level, the financial participation of local citizens in energy projects can be a very successful toolkit to increase the acceptance of the local population. It is not mandatory to implement any financial participation in renewable energy projects, but such measures should at least be offered, if the local population is directly affected by new projects like, for example, wind farms in the direct vicinity of settlements. Many studies exist, that show a direct correlation between a financial participation (e.g., reduced power price or citizen-owned wind farms) in a specific wind farm and the acceptance of the local population toward that wind farm in industrialized countries (cf. [50-52]). The participation is sometimes understood as the financial compensation for perceived negative effects, such as noise [53]. However, the implementation of a financial participation is, depending on the type of participation, sometimes accompanied by work that is required to found or manage a corporation. The author of this article herself has gained experience in a former position as a wind farm planner, where financial participation sometimes failed due to different reasons. Excessive demands or disagreement from locals or the fact that voluntary and unpaid work needs to be done can make the implementation of a financial 
participation difficult. However, if the local population is willing to participate in such activities, a financial participation should be offered and implemented. The question remains: is it possible for a financial participation to be implemented in developing countries, as financial resources are limited in poorer regions? One possible way of finding an answer to such an approach would be to analyze the regional challenges and opportunities together with the local population in a transparent manner.

\subsubsection{Legal Requirements}

The category "legal requirements" mainly consists of three important aspects: legal aspects; standards, codes, and certification; and the elimination of administrative barriers. All the following criteria are important because a proper legal framework guarantees the protection of intellectual property rights (IPR) as well as the trade of technology under certain environmental-related restrictions.

The term "legal aspects" covers a very broad field and encompasses criteria that tackle the planning of new power plants or legal questions such as the access to the power or gas grid. The construction of new power plants needs to be possible without unnecessary restrictions and under well-defined frameworks. The conduction of an environmental impact assessment (EIA) during the planning process of newly constructed power plants is one example to follow a systematic process. A variety of environmental-related information needs to be collected during the planning phase of a new power plant to enable the planning authority to consistently judge and predict whether the project effects on the environment can be compensated and thus, the project can be built [54]. Additionally, a mandatory public consultation and participation allows the local population to be a part of the planning process, which might lead one to find the most socially accepted projects [35]. Like this, the EIA allows a comparable decision-making for authorities and investors. Another application of an impact assessment would be the life-cycle impact assessment at the product level. Governments should carefully take into account how environmentally friendly new products and technologies are produced. In this way, the life cycle of constructing power plants or other products also contribute to reduce overall $\mathrm{CO}_{2}$ emissions as well as, for example, water pollution [55]. Besides the legal basis of project planning, administrative barriers can hinder to implement the transition toward sustainable energy systems. The presence of red tape, complicated procedures or high transaction costs related to knowledge transfer, planning, and implementation can discourage investors to invest in new markets [11]. A further criterion that is mainly important when it comes to the trade of technology is a well-developed framework of standards, codes and certifications. One reason to transform an energy system toward carbon-neutral technologies lies in its sustainability and the prevention of global heating. That is why the equipment also needs to fulfil certain energy efficiency standards, which need to be secured during the trade among countries [12]. The implementation of ecolabels, Environmental management standards (EMS), or other environmental performance standards provides many opportunities "to overcome information barriers, as they allow consumers to be less knowledgeable about the equipment they are purchasing" [12].

\subsubsection{Infrastructure}

According to Pueyo [19], a local infrastructure must be able to deal with a new, transferred technology. By strengthening the existing local economy, as mentioned in the section "strengthening existing economies", existing industries should gain from the benefits that a successful technology transfer enables. Horizontal spillovers across different industries make it easier for investors to build up new companies as not everything, the technology and the know-how, must be imported. Additionally, a good transportation infrastructure is important to be able to build up companies in remote areas [19], where the space for big manufacturing buildings is sufficiently available. A good transportation infrastructure is also important when it comes to the transportation of newly produced big goods, such as big wind turbine blades, for example. If these blades cannot be transported 
to the production side due to a lack of infrastructure, a company will not build up its manufacturing building in such a remote area. However, not just the implementation of roads is important concerning a sufficient technical infrastructure; all aspects of logistics as well as internet connectivity or public services are extremely important for investors to find the right location for a new company. Furthermore, a technological or knowledge spillover can also achieve a certain cost reduction or other local improvements for further research and developments [19]. The aspects of an efficient power grid operation are not mentioned in many of the analyzed literature. Painuly [11] names two criteria concerning the energy grid such as the connectivity to the grid and other system constraints that limit the capacity of the grid. The capacity limitation due to an increased share of decentralized renewable technologies leads in many cases to a curtailment of electricity produced out of intermittent renewable energies, which was already mentioned in the previous section. There are different possibilities to use this electricity instead of curtailing it or expanding the grid substantially. A substantial expansion or improvement of the electricity grid might be necessary, if the existing energy system is very old and entirely based on big, centralized fossil power plants. In this case, the expansion of renewable energies should be accompanied by a substantial grid improvement to guarantee energy security in the future. The decentralized production of hydrogen would be just one possibility. Additionally, the increased importance of sector coupling more and more leads to an increased demand of electricity, which requires a further connection of the gas and electricity grid [56]. The expansion of or the excess to the existing gas grid is currently accompanied by different technical and legal barriers, which are not described in more detail in this section. However, the appropriate policy framework combined with the elimination of technical and legal constraints must enable an efficient use of both energy grids as well as the utilization of currently generated excess power. Furthermore, a necessary technical infrastructure either to charge electrified vehicles or to use green gas on a large scale must be implemented as soon as possible to enable an increased use of such a technology properly. Otherwise, the transition of especially the transportation sector will not be successful.

\subsubsection{Institutions}

The importance of a well-functioning and independent institutional framework is broadly discussed in literature. According to Agenda 21 [14], the access to know-how and the exchange of information can be strengthened by institutional capacities that enable to give informed choices. Developing countries often lack such necessary institutional frameworks, so that a sustainable access to and transfer of environmentally friendly technology is difficult. The construction of a national system of innovation to enable and push the transfer of knowledge, which is crucial for being able to disseminate information, supports the technological development and helps to manage experiences [12]. Such a system connects institutions "to create, store, and transfer the knowledge, skills, and artefacts, which define" [57] opportunities to create new "transfer channels making foreign inputs locally available" [19]. With the focus on knowledge transfer, an eye can be kept on the expansion of so-called social capital [12]. The different dimensions of knowledge were discussed in the category knowledge. It is important to note that national systems of innovation combine public policies, institutions, business, and social relationships, which is why independent nongovernmental organizations play a big role [12]. Independence from governmental views or financing sources is crucial, as unbiased feedback mechanisms are useful to observe and improve markets. It is furthermore important that different channels for the transfer of technology and knowledge are considered because there are different possibilities to make foreign technology and knowledge (inputs) locally available [19]. Besides a well-managed national system of innovation, research and development (R\&D) itself must be possible and promoted in an independent manner. Even if governments are often encouraging R\&D with the help of policies and governmental funding, both public research institutions and private sector R\&D need to be well established, to guarantee an effective information transfer of environmentally friendly technologies [12,14]. Differ- 
ent analyses have shown, that strong governmental support and investment in institutional capacities can help to accelerate the transition toward sustainable energy systems [8]. Additionally, the role of local universities can help to achieve a spillover through the conduction of joint R\&D projects together with local companies [19]. Overall, it can be summarized that independent institutions are crucial for enabling a successful technology and knowledge transfer while disseminating information so that they are understandable for the broad population.

\subsubsection{Clash of Interests}

The category clash of interest deals mainly with the effects of lobbyism. Today, every decision maker should have understood that human activities need to be changed urgently due to the impacts of global heating. Nevertheless, powerful lobbyists work against the transition toward a carbon-neutral energy sector to represent their interests of earning more money with their businesses or business partners. The link of a powerful car lobby with German policy makers is just one prominent example. Between 2009 and 2015, about 13.6 million Euros were donated from the car industry to finance political parties [58]. However, not just the transportation sector is influenced by powerful lobbyists. During the last decades, the coal industry all over the world has put a lot of effort in the consultancy of politicians and international climate negotiations. The coal atlas of 2015 detected many events in which either the coal industry itself or powerful coal lobbyists were trying to advise international politicians in the margins of international climate conferences [59]. These two examples show that the influence of every kind of lobbyism focusing on impeding the transition toward a carbon-neutral economy must be detected and prevented.

\section{Discussion}

This section gives an overview of the limitations of this study, identifies further research areas, and gives recommendations of how a successful transition can be managed.

\subsection{Limitations of Study}

There are some limitations of the presented enabling framework, which need to be mentioned. First, the criteria of different categories depend strongly on each other so that it can be difficult to identify, which of the criteria need to be fulfilled before another. Sometimes, the so-called "chicken-and-egg problem" must be ignored to enable investments in currently not highly used technologies such as the construction of electric charging stations even though the amount of registered electricity cars is still low. In this way, decisions fostering changes in behavior are much easier to realize for the entire society. Additionally, the way of how exactly the criteria can be fulfilled is not fully described in this article. Different countries need to find individual ways that best suit their existing economies. Industrialized countries, having a strong fossil industry, face other challenges compared to developing countries, lacking energy access for all. In this case, the identification and elimination of pervasive fossil subsidies are probably not necessarily important for the developing country but extremely important for the industrialized country. Second, the identification of barriers that currently hinder the transition can be difficult, or there might at least be aspects that are complicated to detect. The decision, for example, of not using available domestic fossil resources, could be difficult to be made by governments, as the use of domestic resources might increase energy independence or gains revenues in case of exportation. Some countries are not seeing the benefits of using domestic renewable resources instead of domestic fossil resources, which is why a stronger awareness needs to be drawn to the negative effects of fossil resource use.

This paper gives explicitly no specific policy suggestions, as some countries are successful with implementing, e.g., quota systems and others with implementing feed-in tariffs to increase their share of renewables. However, without the government willing to focus on carbon-neutral economies, less success might be achieved. 


\subsection{Further Research and Recommendations}

There are mainly three areas where further research is required to guarantee an easier application and further development of the enabling framework:

1. The development of a detailed guideline or step-by-step identification of prevailing barriers and problems. This could also include the development of a comparable and measurable index.

2. The identification of knowledge gaps that currently hinder the transition toward carbon-neutral energy systems.

3. The analysis of individual or general local content requirements to successfully strengthen domestic economies or infrastructure. This includes both the transfer of technology and knowledge.

Some important recommendations can be given that help to implement the aforementioned enabling framework. On the one hand, the criteria which are implemented must guarantee a certain technological neutrality and energy efficiency. Energy efficiency must be fostered to limit the additional amount of electricity that results from sector coupling. The preservation of technological neutrality and the possibility of technological advances must be considered when designing new policy frameworks or long-term goals. In this way, new technologies can benefit from different support mechanisms. The early preselection of special technologies, such as supporting electrical transportation instead of hydrogen transportation, hampers the emergence of least-cost solutions. Furthermore, a mix of different technologies leads to a higher security of supply. On the other hand, the transferability of specific decisions among different countries might be difficult. Some countries have the possibility to invest in the production of, for example, green hydrogen for a sustainable transportation sector, while others do not. This highly depends on the amount of excess power of the entire energy system or the availability of renewable resources. However, the dissemination of best-practice solutions is very helpful and urgently needed for countries with limited possibilities of their own R\&D.

\section{Conclusions}

This paper presents an enabling framework to overcome existing barriers to facilitate sustainable and carbon-neutral technologies at the national level. The literature analysis has shown that most of the analyzed publications are related either to barriers in the electricity sector or to only some of the criteria that are presented in Section 4. The diffusion of, for example, clean technologies is just one important aspect of a successful energy transition, as a new technology alone is not able to compete with established technologies. The transfer of knowledge and the strengthening of the domestic economies are also very important to achieve an understanding for this urgently needed transformation as well as the possibility to gain as many benefits out of the necessary changes as possible.

The enabling framework presented in this paper is at some points not as detailed as presented in other publications. However, criteria such as the protection of the environment or the importance of knowledge are not mentioned or prioritized in other publications but are important parts of the energy transition as a whole. Furthermore, different policy options to support the use of clean technologies exist. The decision on which policy should be chosen must be taken by countries individually, based on the currently installed energy technologies and on the long-term targets that should be achieved.

Science and reality have shown that the technical feasibility of 100\% RES is technically feasible around the world. Even though it took more than a century until coal evolved to be the primary energy source in many countries, the transformation toward the use of carbon-neutral technologies needs to be implemented as soon as possible.

Nowadays, it is about implementing these findings to still be able to limit the impacts of the climate crisis. In recent years, great progress has been made toward the integration and expansion of renewable energies in the electricity sector. However, the transition toward a more sustainable future does not end with the construction of renewable power plants. Substantially larger effort is required to focus on the decarbonization of all sectors 
to achieve a carbon-neutral economy in the near future. Governmental goals must consider both an increasing share of renewables and emission reduction in all areas of the society to enable a sustainable development as well as affordable energy for all.

Funding: The author acknowledges financial support by Land Schleswig-Holstein within the funding program Open Access-Publikationsfonds.

Institutional Review Board Statement: Not applicable.

Informed Consent Statement: Not applicable.

Data Availability Statement: Not applicable.

Acknowledgments: The author is grateful for the comments and valuable feedback of Franziska Dettner during the writing process.

Conflicts of Interest: The authors declare no conflict of interest.

\begin{tabular}{|c|c|}
\hline \multicolumn{2}{|c|}{ Abbreviations } \\
\hline & iations are used in $t$ \\
\hline $\mathrm{CDM}$ & Clean Development Mechanism \\
\hline EIA & Environmental Impact Assessment \\
\hline EMS & Environmental Management Standards \\
\hline EU ETS & European Emission Trading Scheme \\
\hline GCF & Global Climate Fund \\
\hline GEF & Global Environment Facility \\
\hline GHG & Greenhouse gas \\
\hline IPR & Intellectual Property Rights \\
\hline IPP & Independent Power Producer \\
\hline IPCC & Intergovernmental Panel on Climate Change \\
\hline NAMA & Nationally Appropriate Mitigation Action \\
\hline NDC & Nationally Determined Contribution \\
\hline R\&D & Research and Development \\
\hline RES & Renewable Energy System \\
\hline RET & Renewable Energy Technology \\
\hline $\mathrm{TT}$ & Technology Transfer \\
\hline
\end{tabular}

\section{References}

1. United Nations Framework Convention on Climate Change Paris Agreement; United Nations: New York, NY, USA, 2015.

2. Valentine, S.V.; Brown, M.A.; Sovacool, B.K. Empowering the Great Energy Transition: Policy for a Low-Carbon Future; Columbia University Press: New York, NY, USA, 2019; ISBN 978-0-231-18596-7.

3. Hansen, K.; Breyer, C.; Lund, H. Status and perspectives on 100\% renewable energy systems. Energy 2019, 175, 471-480. [CrossRef]

4. Morgan, S. Portugal Erzeugt über 100 Prozent Strom aus Erneuerbaren Energien. Available online: www.euractiv.de (accessed on 12 February 2021).

5. Shearer, C.; Mathew-Shah, N.; Myllyvirta, L.; Yu, A.; Nace, T. Boom and Bust 2019. Tracking the Global Coal Plant Pipeline; Global Energy Monitor, Sierra Club, Greenpeace: Delhi, India, 2019.

6. Rogelj, J.; Shindell, K.; Jiang, K.; Forster, P.; Ginzburg, V.; Handa, C.; Kheshgi, H.; Kobayashi, S.; Kriegler, E.; Mundaca, L.; et al. Mitigation Pathways Compatible with $1.5^{\circ} \mathrm{C}$ in the Context of Sustainable Development. In Global Warming of $1.5^{\circ} \mathrm{C}$; An IPCC Special Report on the Impacts of Global Warming of $1.5^{\circ} \mathrm{C}$ above Pre-Industrial Levels and Related Greenhouse Gas Emission Pathways, in the Context of Strengthening the Global Response to the Threat of Climate Change, Sustainable Development, and Efforts to Eradicate Poverty; IPCC: Geneva, Switzerland, 2018.

7. International Energy Agency Global CO2 Emissions by Sector. 2018. Available online: https://www.iea.org/data-and-statistics/ charts / global-CO2-emissions-by-sector-2018 (accessed on 11 March 2021).

8. Solomon, B.D.; Krishna, K. The coming sustainable energy transition: History, strategies, and outlook. Energy Policy 2011, 39, 7422-7431. [CrossRef]

9. Zerzawy, F.; Fiedler, S.; Mahler, A. Subventionen für Fossile Energien in Deutschland; Greenpeace E.V.: Hamburg, Germany, 2017.

10. Bundesministerium für Wirtschaft undEnergie BMWi-Warum Wurde das EEG Eigentlich Eingeführt? Available online: https: //www.bmwi.de/Redaktion/DE/FAQ/EEG-2017/warum-eeg.html (accessed on 12 February 2021).

11. Painuly, J.P. Barriers to renewable energy penetration; a framework for analysis. Renew. Energy 2001, 24, 73-89. [CrossRef] 
12. Hedger, M.M.; Martinot, E.; Onchan, T. Enabling environments for technology transfer. In Methodological and Technological Issues in Technology Transfer; IPCC; Cambridge University Press: Cambridge, UK, 2000.

13. International Panel on Climate Change. SAR Climate Change 1995: Impacts, Adaptations and Mitigation of Climate Change: ScientificTechnical Analyses_IPCC; Cambridge University Press: Cambridge, UK, 1995.

14. United Nations Conference on Environment E Development Agenda 21; United Nations: New York, NY, USA, 1992.

15. Pueyo, A.; Mendiluce, M.; Naranjo, M.S.; Lumbreras, J. How to increase technology transfers to developing countries: A synthesis of the evidence. Clim. Policy 2012, 12, 320-340. [CrossRef]

16. Bogdanov, D.; Breyer, C. North-East Asian Super Grid for 100\% renewable energy supply: Optimal mix of energy technologies for electricity, gas and heat supply options. Energy Convers. Manag. 2016, 112, 176-190. [CrossRef]

17. Ram, M.; Bogdanov, D.; Aghahosseini, A.; Oyewo, A.; Gulagi, A.; Child, M.; Fell, H.-J. Global Energy System Based on 100\% Renewable Energy - Power Sector; Lappeenrata University of Technology and Energy Watch Grop: Lappeenrata, Berlin, Germany, 2017; ISBN 978-952-335-171-4.

18. Sachverständigenrat für Umweltfragen. Wege zur 100\% Erneuerbaren Stromversorgung: Sondergutachten; Erich Schmidt Verlag GmbH \& Co: Berlin, Germany, 2011; ISBN 978-3-503-13606-3.

19. Pueyo, A. Enabling frameworks for low-carbon technology transfer to small emerging economies: Analysis of ten case studies in Chile. Energy Policy 2013, 53, 370-380. [CrossRef]

20. Naicker, P.; Thopil, G.A. A framework for sustainable utility scale renewable energy selection in South Africa. J. Clean. Prod. 2019, 224, 637-650. [CrossRef]

21. Desgain, D.; Haselip, J. Barriers to the Transfer of Low-carbon Electricity Generation Technologies in Four Latin American Countries. Energy Sources Part. B Econ. Plan. Policy 2015, 10, 348-360. [CrossRef]

22. Ahmadi, M.H.; Ghazvini, M.; Sadeghzadeh, M.; Alhuyi Nazari, M.; Kumar, R.; Naeimi, A.; Ming, T. Solar power technology for electricity generation: A critical review. Energy Sci. Eng. 2018, 6, 340-361. [CrossRef]

23. Bakhtiar, A.; Aslani, A.; Hosseini, S.M. Challenges of diffusion and commercialization of bioenergy in developing countries. Renew. Energy 2020, 145, 1780-1798. [CrossRef]

24. Seetharaman; Moorthy, K.; Patwa, N.; Saravanan; Gupta, Y. Breaking barriers in deployment of renewable energy. Heliyon 2019, 5, e01166. [CrossRef] [PubMed]

25. Beck, F.; Martinot, E. Renewable Energy Policies and Barriers. In Encyclopedia of Energy; Elsevier: Amsterdam, The Netherlands, 2004; pp. 365-383. ISBN 978-0-12-176480-7.

26. Yaqoot, M.; Diwan, P.; Kandpal, T.C. Review of barriers to the dissemination of decentralized renewable energy systems. Renew. Sustain. Energy Rev. 2016, 58, 477-490. [CrossRef]

27. Boselli, F.; Leidreiter, A. 100\% RE Building Blocks. In A Practicle Toolkit for a Sustainable Transition to 100\% Renewable Energy; World Future Council: Hamburg, Germany, 2017.

28. de Leon Barido, D.P.; Avila, N.; Kammen, D.M. Exploring the Enabling Environments, Inherent Characteristics and Intrinsic Motivations Fostering Global Electricity Decarbonization. Energy Res. Soc. Sci. 2020, 61, 101343. [CrossRef]

29. Tietenberg, T.; Lewis, L. Environmental Natural Resource Economics, 9th ed.; Pearson Education: London, UK, 2012.

30. Barbier, E.B.; Markandya, A. A New Blueprint for a Green Economy; Illustrated Edition; Routledge: New York, NY, USA, 2013; ISBN 978-1-84971-353-5.

31. Raworth, K. A Safe and Just Space for Humanity Can We Live within the Doughnut; Oxfam GB: Nairobi, Kenya, 2012.

32. Rockström, J.; Steffen, W.; Noone, K.; Persson, Å.; Chapin, F.S.; Lambin, E.F.; Lenton, T.M.; Scheffer, M.; Folke, C.; Schellnhuber, H.J.; et al. A safe operating space for humanity. Nature 2009, 461, 472-475. [CrossRef]

33. Harris, J.M.; Tufts, U.; Roach, B. Environmental and Natural Resource Economics: A Contemporary Approach, 4th ed.; Taylor \& Francis Ltd.: New York, NY, USA, 2017; ISBN 978-1-138-65947-6.

34. Dettner, F.; Blohm, M. External Costs of Air Pollution from Energy Generation in Morocco. Renew. Sustain. Energy Transit. 2021. under review.

35. Mitchell, C.; Sawin, J.L.; Pokharel, G.R.; Kammen, D.; Wang, Z.; Fifita, S.; Jaccard, M.; Langniss, O.; Lucas, H.; Nadai, A.; et al. Policy, Financing and Implementation. In Renewable Energy Sources and Climate Change Mitigation: Special Report of the Intergovernmental Panel on Climate Change; von Stechow, C., Hansen, G., Seyboth, K., Edenhofer, O., Eickemeier, P., Matschoss, P., Pichs-Madruga, R., Schlömer, S., Kadner, S., Zwickel, T., et al., Eds.; Cambridge University Press: Cambridge, UK, 2011; pp. 865-950. ISBN 978-1-107-02340-6.

36. United Nations Economic and Social Council Progress towards the Sustainable Development Goals; Report of the Secretary-General; United Nations: New York, NY, USA, 2020.

37. Dryzek, J.S.; Niemeyer, S. Deliberative democracy and climate governance. Nat. Human Behav. 2019, 3, 411-413. [CrossRef]

38. Siemens Gamesa Renewable Energy Siemens Gamesa Inaugurates the First Blade Plant in Africa and the Middle East. Available online: https:/ / www.siemensgamesa.com/newsroom/2017/10/siemens-gamesa-inaugurates-the-first-blade-plant-in-africaand-the-middle-east (accessed on 12 February 2021).

39. Rüfer, K. Wer betreibt Kohlekraftwerke in Deutschland? In SUSTAINMENT's BLOG; Available online: https:/ / sustainment.de/ wer-betreibt-kohlekraftwerke-in-deutschland/ (accessed on 19 February 2021).

40. Litz, P. Installed Capacity of Renewable Energies by Ownership. Available online: https://twitter.com/PhilippLitz/status/13507479 $28017645569 /$ photo/1 (accessed on 19 February 2021). 
41. Kemfert, C.; Schäfer, D. Energiwende Braucht Private Investoren; DIW Wochenbericht; Deutsches Institut für Wirtschaftsforschung E.V.: Berlin, Germany, 2013.

42. Disselkamp, M. Unternehmensorganisation: Der Nachteil der Größe. Available online: https://www.focus.de/finanzen/ experten/disselkamp/management-im-wettbewerb-ist-groesse-fuer-firmen-zum-nachteil-geworden_id_7882011.html (accessed on 12 February 2021).

43. Frontier Economics; CE Delft; THEMA Consulting Group; COWI. Potentials of Sector Coupling for Decarbonisation: Assessing Regulatory Barriers in Linking the Gas and Electricity Sectors in the EU: Final Report; Publications Office: Luxembourg, 2019. [CrossRef]

44. Bundesnetzagentur für Elektrizität, Gas, Telekommunikation, Post und Eisenbahn. Bundeskartellamt Monitoringbericht; Bundesnetzagentur für Elektrizität, Gas, Telekommunikation, Post und Eisenbahn: Bonn, Germany, 2020.

45. BloombergNEF Sector Coupling in Europe. Powering Decarbonisation; Bloomberg Finance L.P.: New York, NY, USA, 2020.

46. Oei, P.-Y.; Hermann, H.; Herpich, P.; Holtemöller, O.; Lünenbürger, B.; Schult, C. Coal phase-out in Germany-Implications and policies for affected regions. Energy 2020, 196, 117004. [CrossRef]

47. Oei, P.-Y.; Brauers, H.; Herpich, P. Lessons from Germany's hard coal mining phase-out: Policies and transition from 1950 to 2018. Clim. Policy 2020, 20, 963-979. [CrossRef]

48. Kaufmann, D.; Kraay, A.; Mastruzzi, M. The Worldwide Governance Indicators: Methodology and Analytical Issues. Hague J. Rule Law 2011, 3, 220-246. [CrossRef]

49. Fund, G.C. About GCF. Available online: https://www.greenclimate.fund/about (accessed on 12 February 2021).

50. Olsen, B.E. Renewable Energy: Public acceptance and citizens' financial participation. In Elgar Encyclopedia of Environmental Law; Edward Elgar Publishing Limited: Cheltenham, UK, 2016; ISBN 978-1-78536-952-0.

51. Warren, C.R.; McFadyen, M. Does community ownership affect public attitudes to wind energy? A case study from south-west Scotland. Land Use Policy 2010, 27, 204-213. [CrossRef]

52. Musall, F.D.; Kuik, O. Local acceptance of renewable energy—A case study from southeast Germany. Energy Policy 2011, 39, 3252-3260. [CrossRef]

53. Ott, R.; Keil, S.I. Präferenzen der deutschen Bevölkerung zur Governance bei Windenergieanlagen. Energ. Tagesfr. 2018, 67, 81-85.

54. Glasson, J.; Therivel, R. Introduction to Environmental Impact Assessment, 4th ed.; Routledge: London, UK, 2013; ISBN 978-1-31588121-8. [CrossRef]

55. Hauschild, M.Z. Assessing Environmental Impacts in a Life-Cycle Perspective. Environ. Sci. Technol. 2005, 39, 81A-88A. [CrossRef] [PubMed]

56. Enpower Podcast \#11 Sektorenkopplung, Flexibel Genug? Available online: https://www.enpower-podcast.de/podcast/11 -sektorkopplung-flexibel-genug-prof-dr-martin-wietschel (accessed on 20 February 2021).

57. Metcalfe, J.S. Technology systems and technology policy in an evolutionary framework. Camb. J. Econ. 1995, 19, 25-46. [CrossRef]

58. Lobbyreport 2017 Aussitzen statt Anpacken: Eine Bilanz von vier Jahren Schwarz-Rot; LobbycControl: Köln, Germany, 2017.

59. Heinrich Böll Stiftung and Friends of the Earth. Coal Atlas 2015: Facts and Figures on a Fossil Fuel; Heinrich Böll Stiftung and Friends of the Earth: Berlin, Germany; London, UK, 2017. 